\title{
Protist predation can select for bacteria with lowered susceptibility to infection by lytic phages
}

Anni-Maria Örmälä-Odegrip ${ }^{1,2^{*}}$, Ville Ojala ${ }^{1}$, Teppo Hiltunen ${ }^{3}$, Ji Zhang ${ }^{1,3}$, Jaana KH Bamford ${ }^{1}$ and Jouni Laakso ${ }^{1,2}$

\begin{abstract}
Background: Consumer-resource interactions constitute one of the most common types of interspecific antagonistic interaction. In natural communities, complex species interactions are likely to affect the outcomes of reciprocal co-evolution between consumers and their resource species. Individuals face multiple enemies simultaneously, and consequently they need to adapt to several different types of enemy pressures. In this study, we assessed how protist predation affects the susceptibility of bacterial populations to infection by viral parasites, and whether there is an associated cost of defence on the competitive ability of the bacteria. As a study system we used Serratia marcescens and its lytic bacteriophage, along with two bacteriovorous protists with distinct feeding modes: Tetrahymena thermophila (particle feeder) and Acanthamoeba castellanii (surface feeder). The results were further confirmed with another study system with Pseudomonas and Tetrahymena thermophila.

Results: We found that selection by protist predators lowered the susceptibility to infections by lytic phages in Serratia and Pseudomonas. In Serratia, concurrent selection by phages and protists led to lowered susceptibility to phage infections and this effect was independent from whether the bacteria shared a co-evolutionary history with the phage population or not. Bacteria that had evolved with phages were overall more susceptible to phage infection (compared to bacteria with history with multiple enemies) but they were less vulnerable to the phages they had co-evolved with than ancestral phages. Selection by bacterial enemies was costly in general and was seen as a lowered fitness in absence of phages, measured as a biomass yield.
\end{abstract}

Conclusions: Our results show the significance of multiple species interactions on pairwise consumer-resource interaction, and suggest potential overlap in defending against predatory and parasitic enemies in microbial consumer-resource communities. Ultimately, our results could have larger scale effects on eco-evolutionary community dynamics.

Keywords: Antagonistic co-evolution, Bacteriophages, Host-parasite interaction, Multiple species interaction, Phage resistance, Phage-host interaction, Pseudomonas fluorescens SBW25, Protists, Serratia marcescens, Trade-off

\section{Background}

Consumer-resource interactions are important components of virtually all ecological communities and have been studied extensively as they may determine the stability and diversity of these communities [1]. Experimentally, these interactions are often studied with one-consumer one-resource systems. However, in complex natural communities, any given species interacts with multiple other

\footnotetext{
* Correspondence: anni-maria.ormala@jyu.fi

${ }^{1}$ Centre of Excellence in Biological Interactions, Department of Biological and Environmental, University of Jyväskylä, P.O. Box, 35, 40014 Jyväskylä, Finland ${ }^{2}$ Department of Biosciences, University of Helsinki, P.O. Box 65, 00014 Helsinki, Finland

Full list of author information is available at the end of the article
}

species, and the potential interactions between species increase along with the number of species. Furthermore, in addition to ecological factors, evolution and ecoevolutionary feedbacks have been identified as important components of consumer resource dynamics [2]. In natural communities, bacteriovorous protists and lytic bacteriophages are the most prominent cause of bacterial death, each estimated to account for $50 \%$ of daily bacterial mortality $[3,4]$. Phages are typically highly host-specific while protist grazers choose their prey based on relatively non-specific features, such as prey size [5-7]. Another important difference between protists and phages is that a single protist grazer consumes multiple prey bacteria before reproducing, whereas a successful infection by a 
single parasitic phage results in multiple progeny from a single host bacterium. Defence mechanisms against these two types of enemies can be different: bacteria commonly acquire phage-resistance by altering the cell-surface receptors that the phage uses to gain entrance to the bacterial cell, and common ways to avoid protozoan predation include oversized morphology, cell clustering, biofilm formation, prevention of receptor-mediated phagocytosis, increase in bacterial motility, and secreting toxins against predators $[8,9]$. Due to these profound differences between phages and protists as consumers, they often pose differing selection pressures on bacterial traits. For example, exposure to the ciliate Tetrahymena thermophila has been shown to weaken the antagonistic arms-race co-evolutionary dynamics between Pseudomonas fluorescens and its associated parasitic bacteriophage [10]. However, besides this study, studies that address evolution against both phage and protozoan enemies simultaneously are all but nonexistent.

Pairwise antagonistic co-evolution is predicted to be shaped by the presence of additional interacting species, depending on how the traits that are selected for are correlated [11,12]. Indeed, there are plenty of studies showing negative correlations where the presence of one enemy reduces the evolutionary impact of another species [10,11,13-22]. Negative correlations resulting from multiple species interactions on pairwise antagonistic co-evolution are mostly due to trade-offs between defence mechanisms against multiple enemies, where a benefit from a change in one life-history trait is overridden by the disadvantage introduced by a change in another trait in a given environment $[15,23]$. One study investigating host-parasite and predator-prey interactions with bacteria, phages and protists was conducted with Pseudomonas fluorescens, its associated lytic bacteriophage and Tetrahymena thermophila [10]. The study showed that the presence of two bacterial enemies resulted in divergence of bacteria into specialized defenders against predators and parasites instead of a generalist defensive strategy against both enemies [10]. An example of positively correlated defence mechanisms against multiple enemies was shown in a study where Pseudomonas syringae was allowed to co-evolve with multiple phages: the bacterial hosts evolved resistance against multiple phages simultaneously, but this was accompanied by an associated cost on growth [24]. However, the enemies in this study were all bacteriophages rather than organisms from different taxonomic groups, and all had a parasitic relationship with the host.

In this study, we investigated how the presence of protist predators affects the susceptibility of bacterial to infection by lytic phage. To study this, we used two microbial systems, with either Serratia marcescens or Pseudomonas fluorescens as the focal species. The first microbial community used in this study consisted of the opportunistic pathogen Serratia marcescens, two protist enemies, the particle-feeding ciliate Tetrahymena thermophila and surface-feeding Acanthamoeba castellanii, and a parasite, the lytic bacteriophage Semad11. In order to construct a system mimicking a natural microbial community, we chose two bacteriovorous protists with different modes of feeding. Instead of assessing the individual implications of each predator on the hostparasite relationship between the bacterium and the phage, we investigated how phage-host interaction is shaped in the presence of a more complex community resembling a natural one. The second community consisted of the prey P. fluorescens and the predator T. thermophila. Two alternative hypotheses were proposed: i) if bacterial defence against phages is negatively correlated with defences against protist predators, bacteria in a multi-enemy environment are forced to allocate their limited resources between several costly defences, resulting in lowered defence against phages, and thus elevated susceptibility of bacterial populations to infection by phages (relative to phage-only environment). On the other hand, ii) if bacterial defence against phages and protists is positively correlated, the strong selective pressure posed by multiple enemies is expected to lead to the emergence of bacteria that are less vulnerable to phage infections than bacteria from the phage-only environments. The evolutionary response in bacteria was measured as susceptibility to an infection by either co-evolved or ancestral phages for bacterial populations originating from individual experimental clones. In the Serratia system, bacteria faced with multiple enemies were in general less susceptible to infection by phages, relative to bacteria that had evolved alone or with phages, and this was independent from whether the bacteria shared a co-evolutionary history with the phage population or not. Bacteria that had evolved with phages alone were overall more susceptible to phage infection, but less vulnerable against the phage population they had co-evolved with. Selection by both, phages alone and phages and protists together, came with a cost on the bacterial competitive ability, measured as yield of bacterial biomass in absence of phages. These results were confirmed by the Pseudomonas system; the bacteria that had evolved with Tetrahymena were less susceptible to infection by phages, compared to bacteria that had evolved alone. Our findings show that the presence of protist predators could indirectly select for lowered susceptibility to infection by lytic phages, indicating that some of the evolved anti-predatory traits can also be beneficial against phage infections.

\section{Methods}

\section{Study species and selection experiment}

The organisms used in this study consist of the opportunistic bacterial pathogen Serratia marcescens strain Db11 
[25], Pseudomonas fluorescens strain SWB25 [26], the lytic bacteriophage Semad11 infecting Serratia and the phage SWB25Ф2 infecting Pseudomonas. As predatory protists, we used the particle-feeding ciliate Tetrahymena thermophila (ATCC 30008, obtained from the American Type Culture Collection) and the surface-feeding amoeba Acanthamoeba castellanii (strain CCAP 1501/10, obtained from the Culture Collection of Algae and Protozoa, Freshwater Biological Association, The Ferry House, Ambleside, United Kingdom).

We carried out two selection experiments where bacteria were exposed to protozoan predation. The first selection experiment with the Serratia systems was carried out in static batch culture microcosms $\left(25 \mathrm{~cm}^{2}\right.$ Sarstedt flasks with $15 \mathrm{ml}$ of NAS [New Cereal Leaf - Page's modified Neff's amoebae saline] medium at $25^{\circ} \mathrm{C}$. NAS medium was prepared as follows: $1 \mathrm{~g}$ of cereal grass powder [Aldon Corp., Avon, NY] was boiled in 1 liter of $\mathrm{dH}_{2} \mathrm{O}$ for 5 minutes, and then filtered through a glass fiber filter [GF/C, Whatman]. After cooling down, PAS stock solutions II and I were added, $5 \mathrm{ml}$ each, and $\mathrm{dH}_{2} \mathrm{O}$ was used to restore a final volume of 1 liter [27-29]. Microcosms were seeded either with 1 . Db11 $\left(6.7 \times 10^{7} \mathrm{cfu} /\right.$ $\mathrm{mL})$, 2. Db11 $\left(6.7 \times 10^{7} \mathrm{cfu} / \mathrm{mL}\right)$ and Semad11 $\left(6.7 \times 10^{5}\right.$ $\mathrm{pfu} / \mathrm{mL})$, or 3 . Db11 $\left(6.7 \times 10^{7} \mathrm{cfu} / \mathrm{mL}\right)$, Semad11 $(6.7 \times$ $\left.10^{5} \mathrm{pfu} / \mathrm{mL}\right), T$. thermophila $\left(6.7 \times 10^{2}\right.$ ind. $\left./ \mathrm{mL}\right)$ and $A$. castellanii $\left(6.7 \times 10^{2}\right.$ individuals $\left./ \mathrm{mL}\right)$. Sixteen replicate microcosms were propagated for each treatment. Microcosms were cultured for eight weeks (approximately 50 to 100 bacterial generations) [30], and resources were renewed by substituting $50 \%$ of the medium with fresh NAS each week. Four batch cultures from each treatment were destructively sampled after $1,3,5$, and 8 weeks of co-evolution. The control treatment containing only bacteria had 18 replicate microcosms (five sampled after weeks 1 and 3, and four sampled after weeks 5 and 8). Ten bacterial clones were isolated from each microcosm at each time point for growth analyses $(\mathrm{n}=340)$.

The second selection experiment was carried out in a Pseudomonas and Tetrahymena system without the phage. Details of this experiment are reported in Hiltunen and Becks [31]. In brief: the culture medium for bacteria contained M9 salts and King's B nutrients in a 5\% concentration compared to full strength medium (concentrations used: $1 \mathrm{~g}$ Peptone number 3 and $0.5 \mathrm{ml}$ glycerol in 1 liter of $\mathrm{dH}_{2} \mathrm{O}$ ). With this system, we conducted a 28-day long microcosm experiment, representing approximately 160 Pseudomonas generations. All treatments started from a single ancestral smooth colony of Pseudomonas (i.e. initial genetic variability in the prey population was minimized). All treatments were replicated three times in $25 \mathrm{ml}$ glass vials containing $6 \mathrm{ml}$ of 5\% King's B media. Every 48 hours, $2.5 \%$ of each culture was transferred into a new vial containing fresh culture medium. Microcosms were kept in $28^{\circ} \mathrm{C}\left( \pm 0.1^{\circ} \mathrm{C}\right)$ with constant shaking at $50 \mathrm{rpm}$. During each transfer, both predator and prey abundances were estimated, and a $0.5 \mathrm{ml}$ subsample was frozen with $0.5 \mathrm{ml}$ of $80 \%$ glycerol and kept at $-80^{\circ} \mathrm{C}$ for later analysis. Ciliates do not survive freezing under these conditions. From the last sampling point of this experiment, we isolated 10 bacterial clones from the treatment with bacteria alone (Figure two a in Hiltunen and Becks [31]) and from the treatment with bacteria and ciliates (Figure two $\mathrm{c}$ in Hiltunen and Becks [31]). The rationale for testing both Serratia and Pseudomonas sp. was to confirm that results are not species-specific.

\section{Measuring bacterial growth ability}

Bacterial growth ability was measured as optical density which is known to correlate with dry weight across different organisms [32]. In the Serratia system measurements were done with Bioscreen $\mathrm{C}^{\circ}$ spectrophotometer (420-580 nm wideband filter) on 100-well "Honeycomb 2" plates (Oy Growth Curves Ab Ltd) for all isolated bacterial clones $(n=340)$. Approximately $10^{5}$ bacterial cells grown to late log phase in NAS-medium were inoculated in $400 \mu \mathrm{l}$ of NAS medium in each well. Three replicates were used for each bacterial clone. For the Pseudomonas system cultures were kept at $28^{\circ} \mathrm{C}$ and optical density $(600 \mathrm{~nm})$ for all isolated clones $(\mathrm{n}=20)$ was measured once after 12 hours (UV-1800 spectrophotometer, Shimadzu, Japan).

\section{Measuring the susceptibility of bacterial populations to infection by phages}

To assess the susceptibility of bacterial populations to infection by phages, bacterial growth of isolated bacterial clones was monitored as optical density with and without phages. The susceptibility of a bacterial population (originating from a single clone) for an infection by a given phage population was measured as the difference in optical density between bacteria grown in the presence and absence of phages. For the Serratia system measurements were done on 100-well "Honeycomb 2" plates in $400 \mu \mathrm{l}$ of NAS medium and measured with Bioscreen $\mathrm{C}^{\circ}$ plate reader $(420-580 \mathrm{~nm})$ for $48 \mathrm{~h}$ at $25^{\circ} \mathrm{C}$. Evolved phage populations were isolated from microcosms by centrifugation, and samples were treated with chloroform. Co-evolved phages (unknown population density) or ancestral phages $\left(\sim 10^{5} \mathrm{pfu}\right)$ were inoculated simultaneously with bacterial inoculums in the measurements where phages were included.

\section{Data analysis}

\section{Bacterial growth parameters}

Bacterial yield was determined as the highest arithmetic mean of untransformed OD values in the 25-point sliding time window data. OD of the background medium 
was subtracted from all OD values. Mean maximum yield was calculated for each clone by using the three replicates from the treatments without phage addition. Furthermore, intra-microcosm variation was controlled by calculating a mean maximum yield for each microcosm.

\section{Bacterial susceptibility to phage infections, 'Phage effect'}

To quantify the susceptibility of bacteria to an infection by a phage population we created a variable "Phage effect", describing the mean maximum decrease in optical density per time series caused by phage addition (by coevolved or ancestral phages). For this, the optical density of bacterial growth was monitored 1) in absence or 2) presence of phages, and each clonal measurement had three replicates. The three growth curves obtained for each bacterial clone were used to create 1000 new growth curves by permutation. Thus, in these 1000 created growth curves, a single value for a given time point could originate from any of the three replicate measurements. This procedure was done to mitigate the effect of potential unexplained variation between the three replicate measurements on the 'Phage effect' variable. Subsequently, the 1000 new growth curves for each bacterial clone from phage-containing and phage-free treatments were superimposed, and the mean of maximum decrease in optical density caused by phage addition was designated the phage effect of a given phage type (ancestral or coevolved). Furthermore, we calculated a mean phage effect for each of the 10 clones isolated from a given microcosm to control for intra-microcosm variation. This mean phage effect for a microcosm value was the dependent variable when comparing phage resistance between bacteria with phage-only and multi-enemy coevolutionary histories. For the Pseudomonas system, we compared the difference between optical density of cultures grown alone and cultures grown with the ancestral phage.

\section{Statistical analyses}

The effect of time on dependent variables (ancestral and co-evolved phage effects and yield) was tested for each treatment (phage-only, multi-enemy, no enemies) using one-way ANOVA and the Games-Howell post-hoc test for multiple comparisons when needed. Bacterial phage resistance to both the co-evolved and the ancestral phage was compared between the bacteria that had co-evolved with the phage only and the bacteria that had co-evolved with multiple enemies using Mann-Whitney's U-test. The phage resistance observed was also compared between ancestral and contemporary phage infection treatments; this was done separately for phage-only and multi-enemy bacteria, again using Mann-Whitney's U-test. One-way ANOVA was used to see whether there were differences in yield between ancestral, phage-only, multi-enemy and no-enemies bacteria. Post-hoc multiple comparisons were performed with the Games-Howell test. All analyses were performed with $\mathrm{IBM}^{\circ} \mathrm{SPSS}^{\circ}$ statistics, version 20.

\section{Results}

In the Serratia system, the four experimental weeks did not differ in terms of co-evolved "phage effects" (phageonly: $F_{3,12}=0.648, p=0.599$; multi-enemy: $F_{3,12}=0.566$, $p=0.640$ ), ancestral phage effects (phage-only: $F_{3,12}=$ 4.443, $p=0.026$; multi-enemy: $F_{3,12}=1.017, p=0.419$ ), maximum growth rates (phage-only: $F_{3,12}=1.435, p=$ 0.281 ; multi-enemy: $F_{3,12}=0.418, p=0.743$; no enemies: $F_{3,14}=0.276, p=0.842$ ) or yields (phage-only: $F_{3,12}=$ 2.997, $p=0.073$; multi-enemy: $F_{3,12}=0.172, p=0.913$; no enemies: $\left.F_{3,14}=0.104, p=0.956\right)$. Therefore, the data from the four sampling points was pooled for all the response variables.

\section{Bacterial susceptibility to phage infections}

In the Serratia system, bacteria that had a co-evolutionary history with multiple enemies (phage, ciliate and amoeba) were less susceptible to infection by Semad11 than bacteria that had co-evolved with only a single phage enemy. This applied to both co-evolved (Mann-Whitney $U=43.0, n=$ 16, $p=0.001$ ) and ancestral phages (Mann-Whitney $U=$ 10.0, $n=16, p<0.001$ ) (Figure 1).

Bacteria with a phage-only history were less susceptible to their co-evolved phages than to the ancestral phage (Mann-Whitney $U=201.0, n=16, p=0.006$ ). Conversely, bacteria with multi-enemy history less susceptible to the ancestral phage than to their co-evolved phages (MannWhitney $U=61.0, n=16, p=0.012$ ).

In the Pseudomonas system, bacteria that had evolved with Tetrahymena were less susceptible to infection by phage, compared to bacteria that had evolved alone in the same conditions (Figure 2, $F_{1,4}=36.7 ; p=0.004$ ).

\section{Bacterial growth ability}

Bacteria that had evolved in the absence of enemies had a higher yield than ancestral, phage-only or multi-enemy bacteria $\left(F_{3,109}=55.608, p<0.001\right.$, Figure $3 \mathrm{~b}$; ancestor vs. no enemies: $p<0.001$; phage-only vs. no-enemies: $p<$ 0.001 ; phage-only vs. no-enemies: $p<0.001$ ). Phage-only bacteria had a higher yield compared to ancestral bacteria $(p<0.001)$.

\section{Discussion}

In this study, we demonstrate that the presence of the particle-feeding ciliate Tetrahymena thermophila and surface-feeding amoeba Acanthamoeba castellanii selected for Serratia marcescens that were less vulnerable to an infection by lytic bacteriophages, in comparison to bacteria from phage-only systems (Figure 1). These results were further supported by another study system 


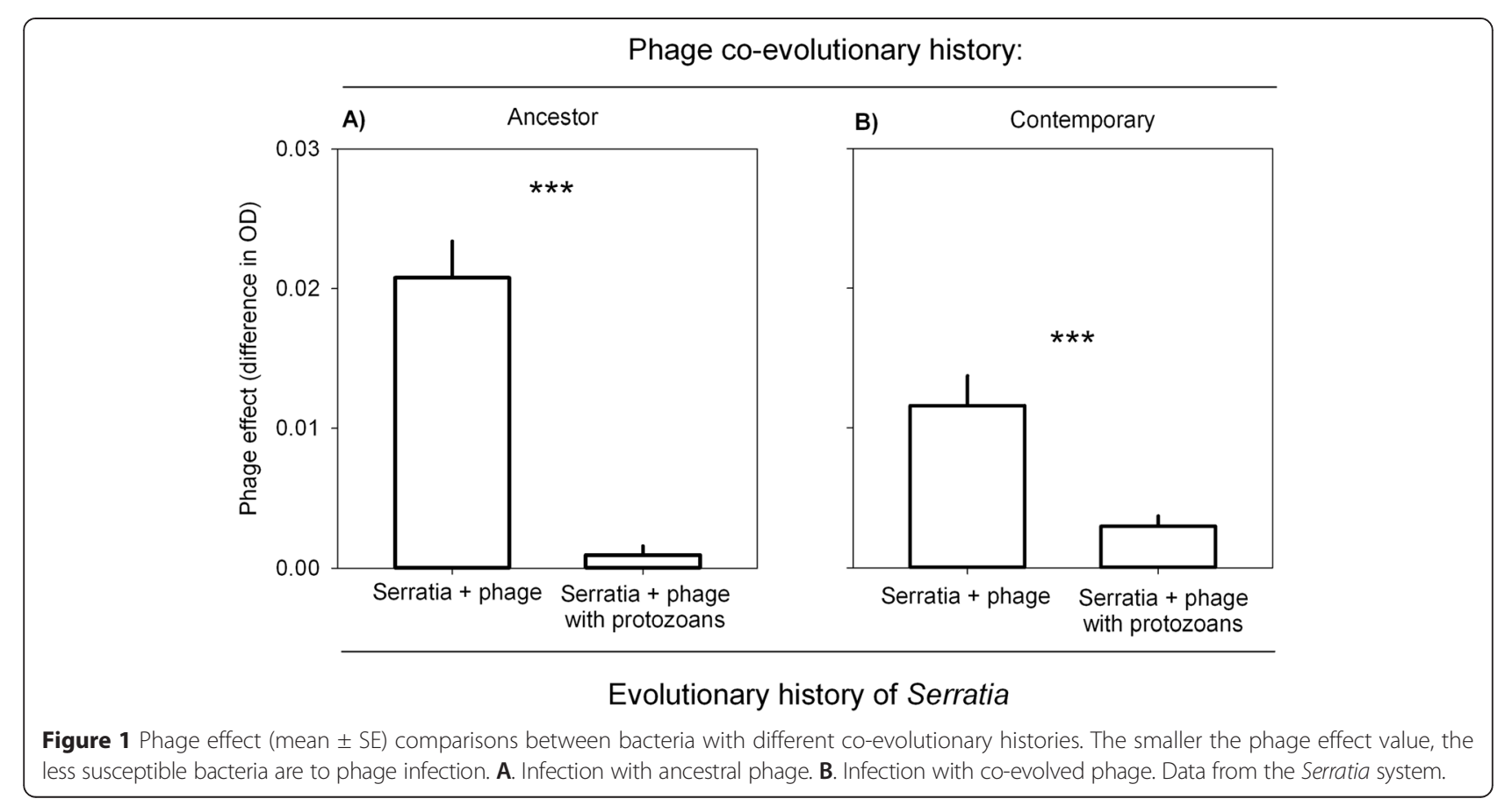

where Pseudomonas bacteria evolved with Tetrahymena ciliate (Figure 2).

Serratia that had evolved in the phage-only systems were more susceptible to the ancestral phage than to coevolved phages (Figure 3). This result is in line with a study by [33] demonstrating that bacteria are most resistant to their contemporary phages in a low-productivity environment. The dominating bacterial defence against phages was thus selective for phage type, potentially through alterations in the surface structures on that the

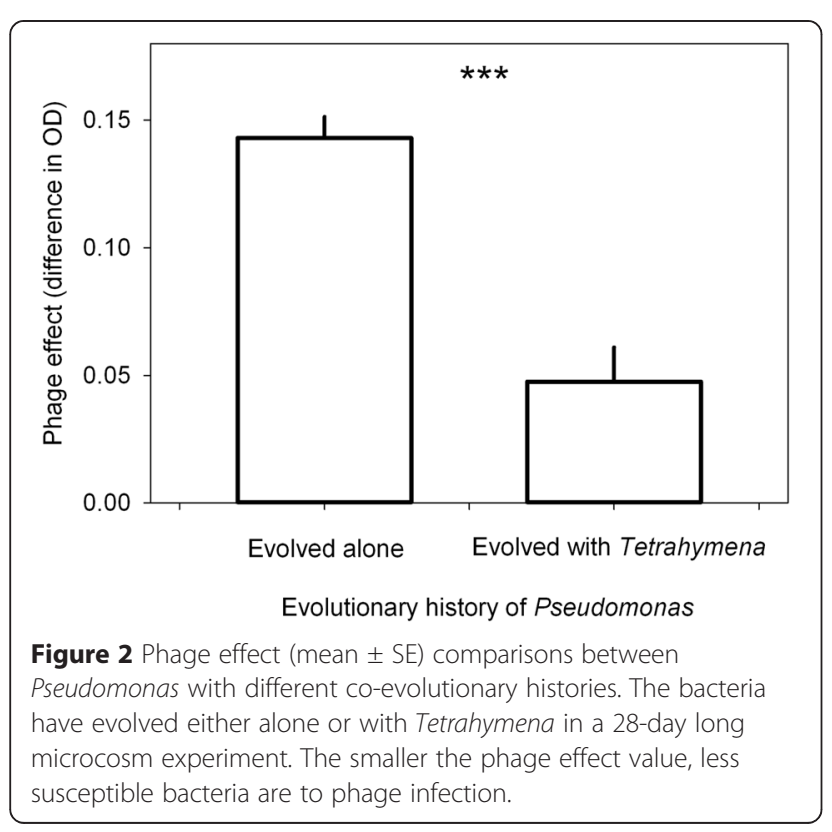

phages recognize. However, the Serratia that had evolved with the phages and protist predators, were less susceptible to infection by both contemporary and ancestral phages, relative to bacteria that had evolved alone. This suggests that some of the evolved anti-predatory traits

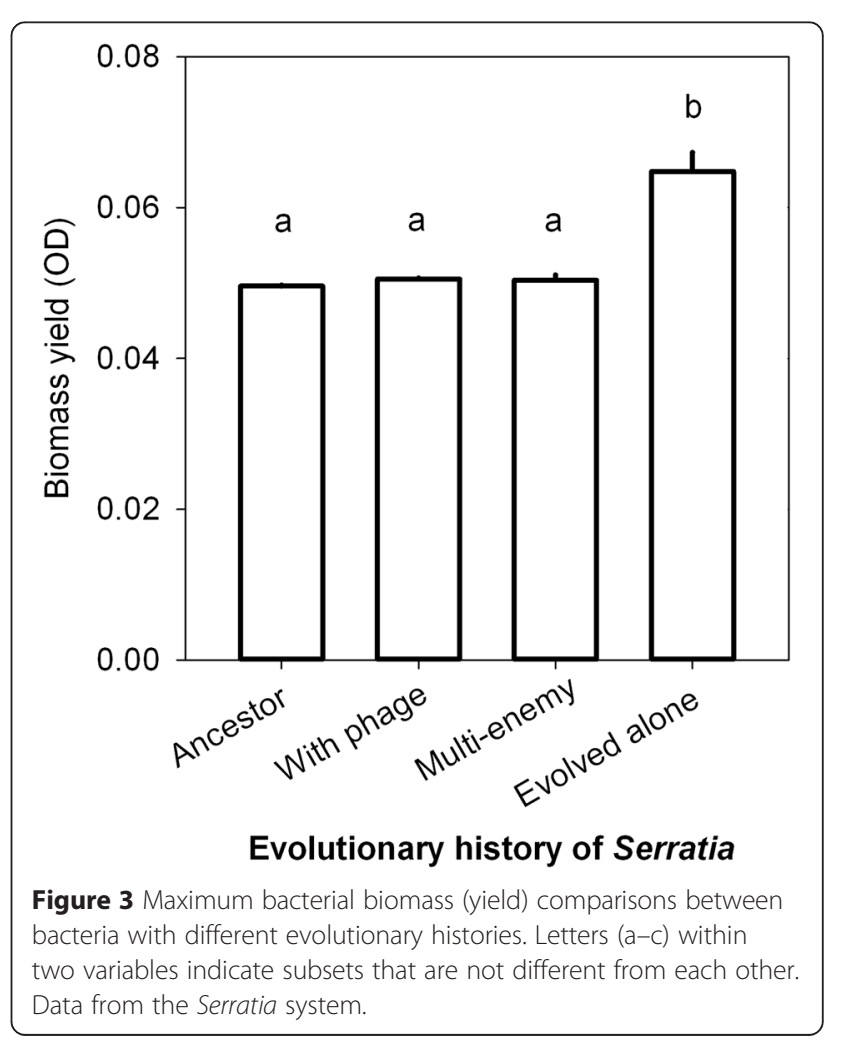


could be also beneficial against phage infection, and this mechanism was less selective to phage type. One such less selective mechanism to avoid infection by phages on bacterial population level could be the production of biofilm, allowing some bacteria to hide from phages as spatial refugees [34]. Furthermore, biofilm formation has been shown to increase in bacteria in the presence of many phages [35] as well as the protist T. thermophila [36] and moreover, Semad11 has been shown not to have any negative long-term effects on $S$. marcescens biofilm biomass in aquatic systems [30]. In addition to biofilm formation, colony formation is known to be used as a defence against protist predation [9] and indeed, observation of liquid cultures under a light microscope indicates that both of the bacterial species used in this study evolve colony defences against grazing by $T$. thermophila within a week. In addition to phages, amoebas are also able to recognize surface structures of bacteria prior to phagocytosis [37]. One potential mechanism through which bacteria could escape both phage and amoeba predation is masking of receptors on the cell surface by producing extracellular polymer structures, providing a physical barrier between the enemies and their receptors. Low resource environments can select for bacteria with high competitive ability [38], which is likely to account for the increased bacterial yield in the Serratia system with no enemies. However, the evolution for increased biomass yield was constrained by the presence of phages, and phages and protists together, likely through costs associated with antipredatory and antiparasitic defence traits.

Our results can have implications beyond the ecoevolutionary community effects presented here, since many bacteria that actively grow in natural multispecies reservoirs can also opportunistically cause infections in multicellular organisms [39]. One example of this type of opportunistic bacteria is $S$. marcescens used in this study. As life in natural reservoirs and possessing virulence against multicellular hosts pose distinct challenges for bacteria, their life-history in natural reservoirs may be expected to have implications for virulence. More specifically, bacterial antipredatory defence traits are often traded off with competitive ability (indicated by growth rate or yield in bacteria) [40-44], either through pleiotropy at related genetic loci or through costs associated with resistance mechanisms [45]. Competitive ability in bacteria, in turn, is often linked to virulence, e.g. through the rate at which the host is colonized [46-48]. Phage-resistance has been shown to correlate with lowered pathogenicity in e.g. Serratia marcescens, Bacillus thuringiensis, Vibrio cholerae, Eschericia coli, Klebsiella pneumoniae, and Salmonella species [25,49-53]. As the presence of protists was shown to affect the outcomes of bacterial susceptibility for phage infection, along with growth ability in S. marcescens, our findings interestingly suggest that the enemy composition in natural reservoirs of bacterial opportunists could have implications for the virulence of opportunistically pathogenic bacteria.

\section{Conclusions}

In conclusion, we tested how bacterial susceptibility to an infection by a parasitic phage and the potential associated cost on the competitive ability of the bacterium is modified by the presence of a community of protist bacterivores. Bacteria that had evolved with multiple enemies were overall less susceptible to infection, by both ancestral, and contemporary phages. Pairwise co-evolution with phages led to a specific defence against phages, where bacteria were more resistant to the contemporary phages than the ancestral phages. Allocation to defence was costly for the bacterium in general, constraining the evolution for increased bacterial yield in all systems. Our study is among few studies showing the implications of multiple species interactions on an evolving host-parasite system, and it suggests a previously unreported overlap of bacterial defence against predation and parasitism in microbial consumer-resource communities.

\section{Availability of supporting data}

The data sets supporting the results of this article are available online in the Dryad data repository under doi:10.5061/ dryad.s64vm [54].

\section{Competing interests}

The authors declare that they have no competing interests.

\section{Authors' contributions}

AMÖO and JZ designed and carried out the selection experiment with Serratia marcescens, which was designed by AMÖO, JZ and JL. Phage-resistance and growth experiments with S. marcescens were designed by AMÖO and VO and conducted by VO. Statistical analyses for experiments with S. marcescens were performed by VO and JL. TH designed and conducted the experiments with Pseudomonas fluorescens and performed the related statistical analyses. The manuscript was drafted and written by AMÖO, VO, TH and JL. The project was coordinated and infrastructure and materials provided by JB. All authors have read and approved the final version.

\section{Acknowledgements}

The study was financed by the Academy of Finland, grants \#1130724 and 1255572 (Jouni Laakso), and by the Academy of Finland's Centre of Excellence (CoE) programs: CoE in Virus Research (2006-2011) grant \#1213467 (Jaana Bamford), and CoE in Biological Interactions (2012-2017) grant \#252411 (Johanna Mappes). Ji Zhang received funding from the Finnish Cultural Foundation, Biological Interactions Graduate School (BIOINT), and Ellen and Artturi Nyyssönen Foundation. We also thank J. Cairns for editing the English.

\section{Author details}

${ }^{1}$ Centre of Excellence in Biological Interactions, Department of Biological and Environmental, University of Jyväskylä, P.O. Box, 35, 40014 Jyväskylä, Finland.

${ }^{2}$ Department of Biosciences, University of Helsinki, P.O. Box 65, 00014 Helsinki, Finland. ${ }^{3}$ Department of Food and Environmental Sciences/ Microbiology and Biotechnology, University of Helsinki, P.O. Box 65, 00014 Helsinki, Finland.

Received: 4 November 2014 Accepted: 27 March 2015

Published online: 07 May 2015 


\section{References}

1. Murdoch WW, Briggs CJ, Nisbet RM. Dynamics of consumer-resource interactions: importance of individual attributes. In: British Ecological Society, Olff H, Brown VK, Drent RH, editors. 38th Symposium of the British Ecological Society: Herbivores: Between Plants and Predators. Oxford: Blackwell Science; 1999. p. 521-50.

2. Hiltunen T, Hairston NG, Hooker G, Jones LE, Ellner SP. A newly discovered role of evolution in previously published consumer-resource dynamics. Ecol Lett. 2014;17(8):915-23.

3. Fuhrman JA, Noble RT. Viruses and protists cause similar bacterial mortality in coastal seawater. Limnol Oceanogr. 1995;40(7):1236-42.

4. Suttle CA. Viruses in the sea. Nature. 2005:437(7057):356-61.

5. Gonzalez JM. Efficient size-selective bacterivory by phagotrophic nanoflagellates in aquatic ecosystems. Mar Biol. 1996;126(4):785-9.

6. Simek K, Vrba J, Lavrentyev P. Estimates of Protozoan Bacterivory - from Microscopy to Ectoenzyme Assay. Marine Microbial Food Webs, 1994, Vol 8, No 1 and 2 1994:71-85

7. Gonzalez JM, Suttle CA. Grazing by marine nanoflagellates on viruses and virus-sized particles - ingestion and digestion. Mar Ecol Prog Ser. 1993;94(1):1-10.

8. Roberts EC, Legrand C, Steinke M, Wootton EC. Mechanisms underlying chemical interactions between predatory planktonic protists and their prey. J Plankton Res. 2011:33(6):833-41.

9. Matz C, Kjelleberg S. Off the hook - how bacteria survive protozoan grazing. Trends Microbiol. 2005;13(7):302-7.

10. Friman VP, Buckling A. Effects of predation on real-time host-parasite coevolutionary dynamics. Ecol Lett. 2013;16(1):39-46.

11. Iwao K, Rausher MD. Evolution of plant resistance to multiple herbivores: Quantifying diffuse coevolution. Am Nat. 1997;149(2):316-35.

12. Strauss SY, Sahli H, Conner JK. Toward a more trait-centered approach to diffuse (co)evolution. New Phytol. 2005;165(1):81-9

13. Sih A, Englund G, Wooster D. Emergent impacts of multiple predators on prey. Trends Ecol Evol. 1998;13(9):350-5.

14. Pitt WC. Effects of multiple vertebrate predators on grasshopper habitat selection: trade-offs due to predation risk, foraging, and thermoregulation. Evol Ecol. 1999:13(5):499-515.

15. Stinchcombe JR, Rausher MD. Diffuse selection on resistance to deer herbivory in the ivyleaf morning glory, Ipomoea hederacea. Am Nat. 2001;158(4):376-88.

16. Thompson JN. Coevolution: the geographic mosaic of coevolutionary arms races. Curr Biol. 2005;15(24):R992-4.

17. Berenbaum MR, Zangerl AR. Parsnip webworms and host plants at home and abroad: Trophic complexity in a geographic mosaic. Ecology. 2006;87(12):3070-81.

18. Craig TP, Itami JK, Horner JD. Geographic variation in the evolution and coevolution of a tritrophic interaction. Evolution. 2007;61(5):1137-52.

19. Edeline E, Ari TB, Vollestad LA, Winfield IJ. Fletcher JM, James JB, et al. Antagonistic selection from predators and pathogens alters food-web structure. Proc Natl Acad Sci U S A. 2008;105(50):19792-6.

20. Siepielski AM, Benkman CW. A seed predator drives the evolution of a seed dispersal mutualism. Proc Biol Sci. 2008;275(1645):1917-25.

21. Gomez JM, Perfectti F, Bosch J, Camacho JPM. A geographic selection mosaic in a generalized plant-pollinator-herbivore system. Ecol Monogr. 2009;79(2):245-63

22. Koskella B, Thompson JN, Preston GM, Buckling A. Local biotic environment shapes the spatial scale of bacteriophage adaptation to bacteria. Am Nat. 2011;177(4):440-51.

23. Davies NB, Brooke MD. An experimental-study of Co-evolution between the cuckoo, cuculus-canorus, and its hosts.2. Host egg markings, chick discrimination and general discussion. J Anim Ecol. 1989;58(1):225-36.

24. Koskella B, Lin DM, Buckling A, Thompson JN. The costs of evolving resistance in heterogeneous parasite environments. P Roy Soc B-Biol Sci. 2012;279(1735):1896-903.

25. Flyg C, Kenne K, Boman HG. Insect pathogenic properties of Serratia marcescens: phage-resistant mutants with a decreased resistance to Cecropia immunity and a decreased virulence to Drosophila. J Gen Microbiol. 1980;120(1):173-81

26. Rainey PB, Bailey MJ. Physical and genetic map of the Pseudomonas fluorescens SBW25 chromosome. Mol Microbiol. 1996;19(3):521-33.

27. La Scola B, Mezi L, Weiller PJ, Raoult D. Isolation of Legionella anisa using an amoebic coculture procedure. J Clin Microbiol. 2001;39(1):365-6.
28. Greub G, Raoult D. Microorganisms resistant to free-living amoebae. Clin Microbiol Rev. 2004;17(2):413. +.

29. Page FC. A new key to freshwater and soil gymnamoebae with instructions for culture. - Freshwater Biological Association. Cumbria: Freshwater Biological Association; 1988

30. Zhang J., Örmälä-Odegrip A-M, Mappes J, Laakso J. Top-down effects of a lytic bacteriophage and protozoa on bacteria in aqueous and biofilm phases. Ecol Evol. 2014; doi: 10.1002/ece3.1302.

31. Hiltunen T, Becks L. Consumer co-evolution as an important component of the eco-evolutionary feedback. Nature communications. 2014. In press.

32. Myers JA, Curtis BS, Curtis WR. Improving accuracy of cell and chromophore concentration measurements using optical density. BMC Biophys. 2013;6:4.

33. Gomez P, Buckling A. Bacteria-phage antagonistic coevolution in soil. Science. 2011;332(6025):106-9.

34. Labrie SJ, Samson JE, Moineau S. Bacteriophage resistance mechanisms. Nat Rev Microbiol. 2010;8(5):317-27.

35. Weiner R, Langille $\mathrm{S}$, Quintero E. Structure, function and immunochemistry of bacterial exopolysaccharides. J Ind Microbiol. 1995;15(4):339-46.

36. Mikonranta L, Friman VP, Laakso J. Life history trade-offs and relaxed selection can decrease bacterial virulence in environmental reservoirs. PLOS ONE. 2012;7(8):e43801.

37. Korn ED, Wright PL. Macromolecular composition of an amoeba plasma membrane. J Biol Chem. 1973;248(2):439-47

38. Bohannan BJM, Lenski RE. The relative importance of competition and predation varies with productivity in a model community. Am Nat. 2000:156(4):329-40.

39. Woolhouse ME, Taylor LH, Haydon DT. Population biology of multihost pathogens. Science. 2001;292(5519):1109-12

40. Friman VP, Hiltunen T, Jalasvuori M, Lindstedt C, Laanto E, Ormala AM, et al. High temperature and bacteriophages can indirectly select for bacterial pathogenicity in environmental reservoirs. PLOS ONE. 2011;6(3), e17651.

41. Brockhurst MA, Rainey PB, Buckling A. The effect of spatial heterogeneity and parasites on the evolution of host diversity. P Roy Soc B-Biol Sci. 2004;271(1534):107-11

42. Bohannan BJM, Lenski RE. Effect of prey heterogeneity on the response of a model food chain to resource enrichment. Am Nat. 1999;153(1):73-82.

43. Lenski RE, Levin BR. Constraints on the coevolution of bacteria and virulent phage - a model, some experiments, and predictions for natural communities. Am Nat. 1985;125(4):585-602.

44. Lenski RE. Dynamics of interactions between bacteria and virulent bacteriophage. Adv Microb Ecol. 1988;10:1-44

45. Williams HTP. Phage-induced diversification improves host evolvability. BMC Evol Biol. 2013;13:17

46. Harrison F, Browning LE, Vos M, Buckling A. Cooperation and virulence in acute Pseudomonas aeruginosa infections. BMC Biol. 2006;4:21.

47. Frank SA. Models of parasite virulence. O Rev Biol. 1996:71(1):37-78.

48. de Roode JC, Pansini R, Cheesman SJ, Helinski MEH, Huijben S, Wargo AR, et al. Virulence and competitive ability in genetically diverse malaria infections. P Natl Acad Sci USA. 2005;102(21):7624-8.

49. Gu JM, Liu XH, Li Y, Han WY, Lei LC, Yang YJ, et al. A method for generation phage cocktail with great therapeutic potential. PLoS One. 2012;7(3):e31698.

50. Heierson A, Siden I, Kivaisi A, Boman HG. Bacteriophage-resistant mutants of bacillus-thuringiensis with decreased virulence in pupae of hyalophora-cecropia. J Bacteriol. 1986;167(1):18-24.

51. Santander J, Robeson J. Phage-resistance of Salmonella enterica serovar Enteritidis and pathogenesis in Caenorhabditis elegans is mediated by the lipopolysaccharide. Flectron J Biotechn. 2007:10(4):627-32.

52. Smith HW, Huggins MB. Effectiveness of phages in treating experimenta escherichia-coli diarrhea in calves, piglets and lambs. J Gen Microbiol. 1983;129(Aug):2659-75.

53. Zahid MSH, Udden SMN, Faruque ASG, Calderwood SB, Mekalanos JJ, Faruque SM. Effect of phage on the infectivity of vibrio cholerae and emergence of genetic variants. Infect Immun. 2008;76(11):5266-73.

54. Örmälä-Odegrip AM, Ojala, V, Hiltunen T, Zhang J, Bamford JKH, Laakso T. Bacterial growth and 'Phage effect' data from Serratia and Pseudomonas systems. 2015. doi:10.5061/dryad.s64vm. 